
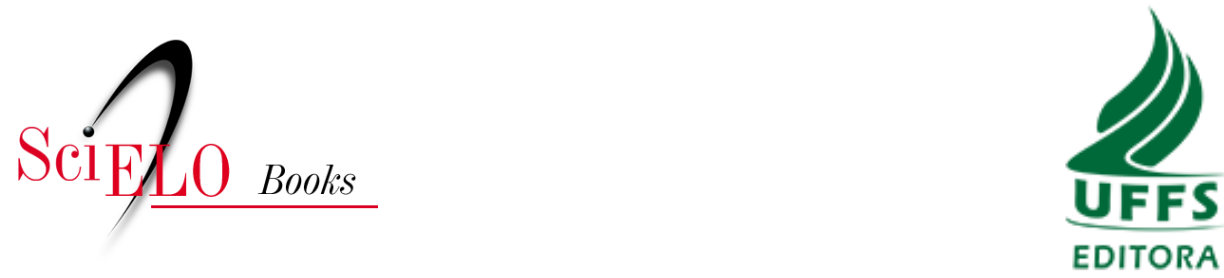

\title{
Parte VII - Desenvolvimento e políticas públicas Capítulo 8 - Saneamento básico na região das missões: realidade e desafios na implantação de políticas públicas que promovam o desenvolvimento
}

\author{
Luís Henrique Teixeira Franqui \\ Edemar Rotta
}

\section{SciELO Books / SciELO Livros / SciELO Libros}

FRANQUI, L.H.T., and ROTTA, E. Saneamento básico na região das missões: realidade e desafios na implantação de políticas públicas que promovam o desenvolvimento. In: ROTTA, E., LAGO, I.C., JUSTEN, A.F., and SANTOS, M., eds. Conhecimento em rede: desenvolvimento, cooperação e integração regional em território de fronteira - Rede CIDIR: 10 anos [online]. Chapecó, SC: Editora UFFS, 2019, pp. 557-578. ISBN: 978-65-5019-011-8. https://doi.org/10.7476/9786586545432.0033.

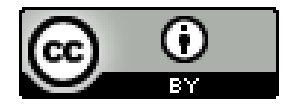

All the contents of this work, except where otherwise noted, is licensed under a Creative Commons Attribution 4.0 International license.

Todo o conteúdo deste trabalho, exceto quando houver ressalva, é publicado sob a licença Creative Commons Atribição 4.0. 


\title{
SANEAMENTO BÁSICO NA REGIÃO DAS MISSÕES: REALIDADE E DESAFIOS NA IMPLANTAÇÃO DE POLÍTICAS PÚBLICAS QUE PROMOVAM O DESENVOLVIMENTO
}

\author{
Luís Henrique Teixeira Franqui ${ }^{1}$ \\ Edemar Rotta ${ }^{2}$
}

\section{INTRODUÇÃO}

A definição legal de saneamento básico, por meio da Lei no 11.445/2007, considera o conjunto de serviços, infraestruturas e instalações operacionais de

1 Mestre em Desenvolvimento e Políticas Públicas pela Universidade Federal da Fronteira Sul (UFFS, 2017) - Campus Cerro Largo. Graduado em Direito pelo Instituto Cenecista de Ensino Superior de Santo Ângelo (IESA, 2015). Jornalista. Advogado. Contato: lhfranqui@hotmail.com

2 Pós-Doutor em Serviço Social (PUCRS, 2017). Doutor em Serviço Social (PUCRS, 2007). Mestre em Sociologia (UFRGS, 1988). Graduado em Filosofia pela Faculdade de Filosofia, Ciências e Letras Dom Bosco (1985). Professor Adjunto da Universidade Federal da Fronteira Sul (UFFS) - Campus Cerro Largo. Contato: erotta@uffs.edu.br 
abastecimento de água potável, esgotamento sanitário, limpeza urbana e manejos de resíduos sólidos, drenagem e manejo das águas pluviais (BRASIL, 2007). Em todo o mundo, cerca de 1,3 bilhão de toneladas de resíduos sólidos são produzidas anualmente nas cidades. De acordo com o Banco Mundial (relatório "What a Waste: A Global Review of Solid Waste Management"), a geração de lixo ${ }^{4}$ per capita quase dobrou nos últimos anos, chegando à segunda década do milênio a $1,2 \mathrm{Kg} / \mathrm{pessoa} / \mathrm{dia}$. As projeções para 2025 indicam que esse valor passe para $1,42 \mathrm{Kg} /$ pessoa/dia, ampliando para cerca de 2,2 bilhões de toneladas anuais nos espaços urbanos mundiais. Contudo, é preciso ressaltar que essas médias variam consideravelmente de país para país, região, cidade e até mesmo dentro das cidades (WORLD BANK, 2012, p. 8).

Segundo dados da Associação Brasileira de Empresas de Limpeza Pública e Resíduos Especiais (ABRELPE), "a geração total de RSU no Brasil em 2014 foi de aproximadamente 78,6 milhões de toneladas, o que representa um aumento de 2,9\% de um ano para outro, índice superior à taxa de crescimento populacional no país no período, que foi de 0,9\%" (ABRELPE, 2014, p. 28). Esses números demonstram que a geração de Resíduos Sólidos Urbanos (RSU) per capita no país, em 2014, ficou em 387,63 Kg/ano, ou 1,062 Kg/ pessoa dia, situando-se um pouco abaixo da média per capita mundial. Além da questão relacionada à geração de RSU, num ritmo acelerado e crescente, alicerçado no consumismo, que Bauman (2008, p. 19) classificou como "sociedade de consumidores", os municípios brasileiros enfrentam graves problemas relacionados à coleta e à destinação final desses resíduos.

Atualmente, um dos grandes problemas ambientais enfrentados pela humanidade é recolher, depositar e tratar corretamente o enorme volume de resíduos sólidos urbanos (RSU), que afeta o equilíbrio ambiental pela liberação de gases que colaboram com o efeito estufa, bem como pela poluição das águas, sendo causa de prejuízos financeiros, diretos e indiretos. Para Franqui (2016, p. 1), "dar o correto destino aos RSU não é apenas uma questão legal, para cumprir

3 Que desperdício: uma revisão global da gestão de resíduos sólidos. (Tradução livre).

4 Lixo é entendido, aqui, no sentido amplo, correspondendo a todos os resíduos gerados pela atividade humana e considerados sem utilidade. 
a legislação vigente, mas uma exigência visando garantir os anseios por um meio ambiente equilibrado e sustentável para as presentes e futuras gerações ${ }^{5 "}$.

Em agosto de 2014, expirou o prazo determinado pela Política Nacional de Resíduos Sólidos (PNRS, Lei no 12.305/2010), para que os 5.570 municípios brasileiros acabassem com os chamados "lixões". Finda a data-limite estabelecida na PNRS, um número muito grande de municípios ainda não conseguiu substituir os lixões por aterros sanitários. De acordo com o Panorama dos Resíduos Sólidos no Brasil 2014, da ABRELPE (2015, p.31), em relação à destinação final dos RSU coletados no Brasil, 58,4\% (41,6 milhões de toneladas/ano) do volume total produzido teve destino adequado, enquanto 41,6\% (29,6 milhões de toneladas/ano) foram destinados inadequadamente, sendo despejado em lixões ou "em sua versão apenas um pouco menos nociva, os aterros controlados" (ABRAMOVAY et al., 2013, p. 21). O índice de 58,4\% de destinação final adequada, em 2014, é bastante significativo, porém a quantidade de RSU destinada a locais inadequados totaliza 29.659.170 toneladas no ano, ou seja, seguiram para lixões ou aterros controlados, os quais, do ponto de vista ambiental, pouco se diferenciam dos lixões, pois não possuem o conjunto de sistemas necessários para a proteção do meio ambiente e da saúde pública (ABRELPE, 2015, p. 30).

Ao produzir o perfil socioeconômico do Conselho Regional de Desenvolvimento das Missões (COREDE Missões), a Secretaria do Planejamento, Mobilidade e Desenvolvimento Regional do Estado do Rio Grande do Sul (SEPLAN, 2015 , p. 7) demonstrou que "a preocupação com o equilíbrio territorial do desenvolvimento é um desafio que devemos nos impor cotidianamente no processo de planejamento e implementação das políticas públicas e, não por acaso, foi eleita como objetivo estratégico do Governo do Estado".

Está claro que, para propor políticas públicas que visem corrigir eventuais deficiências existentes e, por consequência, estimular o desenvolvimento regional, é preciso conhecer a realidade da região, seus problemas e suas potencialidades. Nesse sentido, o estudo que constitui este capítulo objetiva analisar indicadores ligados ao saneamento básico, com especial preocupação na coleta de resíduos sólidos, pois esse é um fator limitador ao desenvolvimento regional.

5 Meio ambiental equilibrado e sustentável para "as presentes e futuras gerações" está relacionado com o desenvolvimento sustentável, encontrado na parte final do caput do art. 225 da Constituição da República Federativa do Brasil (1988), artigo basilar do Direito Ambiental, e amparado na Declaração da Conferência da ONU sobre o Meio Ambiente (Estocolmo, 1972). [grifo nosso] 
O procedimento metodológico terá enfoque qualitativo, sendo a análise de documentos e a revisão bibliográfica as principais técnicas de coleta de dados, informações e fundamentos teóricos para a análise da temática proposta. As principais fontes selecionadas para a pesquisa foram o perfil socioeconômico do COREDE Missões, o Panorama dos Resíduos Sólidos da ABRELPE, a Incubadora Tecnossocial de Cooperativas e Empreendimentos Econômicos Solidários (ITCEES), a Administração Municipal de Cerro Largo e fontes bibliográficas.

O presente capítulo procura apresentar contribuições para análise da realidade regional, discutindo soluções para problemas relacionados ao saneamento básico e à coleta e destinação final dos RSU. Na primeira parte, situa-se a realidade dos municípios da região das Missões, procurando enfatizar aspectos ligados aos desafios que envolvem os temas estudados. Na segunda parte, apresentam-se algumas experiências alternativas em curso na região. Conclui-se com alguns apontamentos sobre os resultados obtidos, na direção de suscitar novas investigações e proposições.

\section{COREDE MISSÕES, GARGALOS DO DESENVOLVIMENTO E DESAFIOS}

Neste estudo adota-se a definição de região proposta pela "constituição dos Conselhos Regionais de Desenvolvimento, tornados referências para a divisão socioterritorial do RS a partir de 1994" (ROTTA et al., 2015, p. 2). Conforme a Fundação de Economia e Estatística ${ }^{6}$ (FEE), a região das Missões é composta por 25 municípios, compreendendo uma área total de 12.855,5 $\mathrm{Km}^{2}$ (2015), o que correspondente a 4,6\% do território gaúcho; apresenta população de 251.076 habitantes (2015) e densidade demográfica de 19,1 habitantes/ $\mathrm{Km}^{2}$ (2013); possui taxa de analfabetismo de pessoas com 15 anos ou mais na ordem de $6,45 \%$ (2010), expectativa de vida ao nascer de 72,08 anos (2000) e coeficiente de mortalidade infantil de 11,09 por mil nascidos vivos (2014).

Esta região possui uma marca histórica representada pela experiência das Missões Jesuíticas, entre os séculos XVII e XVIII" (ROTTA et al., 2015, p. 2). Os primeiros habitantes foram das etnias Guarani, Charrua e Kaingang, seguindo-se

6 Vide: http://www.fee.rs.gov.br/perfil-socioeconomico/coredes/detalhe/?corede=Miss\%F5es. 
experiências reducionais com os padres da Companhia de Jesus e, em período posterior ao fim das reduções, 'aconteceu o processo colonizador do território em questão, fator que, aliado aos anteriores, definirá as características étnico-culturais da população assim como as conhecemos hoje' (RAMOS, 2006, p. 2).

Ramos (2006, p. 19) refere que a "primeira tentativa de instalação de europeus foi em 1824, com a vinda de imigrantes alemães para a região da redução de São João Batista, atual município de Entre-Ijuís". A região conta com a presença de descendentes de diferentes etnias, com destaque para os descendentes alemães, que, após a primeira tentativa, na década de 1820, retornaram no início do século XX. A Companhia de Colonização “Bauerverein” promoveu a venda de lotes de terras na região do assentamento Serro Azul, que abrangia os atuais municípios de Cerro Largo, Roque Gonzales, São Paulo das Missões, Salvador das Missões, Sete de Setembro, Porto Xavier e São Pedro do Butiá (RAMOS, 2006, p. 22).

Também há presença de descendentes de poloneses e suecos em Guarani das Missões, assim como de descendentes de imigrantes italianos. Porém, a presença de italianos não é tão significativa, "pois a vinda desses colonos não ocorreu através de colônias destinadas a estas famílias, mas através de migração das velhas colônias do interior do estado, principalmente do centro e da serra gaúcha" (RAMOS, 2003, p. 23).

\section{Gargalos do desenvolvimento}

O perfil socioeconômico do COREDE Missões, publicado em novembro de 2015, apresenta, de maneira bastante sucinta, vários gargalos que dificultam o desenvolvimento desta região do Rio Grande do Sul. Os problemas já começam a ser verificados com a perda populacional. "Em 2010, o COREDE possuía uma população de 248.016 habitantes, com uma proporção de $71 \%$ de moradores em áreas urbanas e 29\% em áreas rurais" (SEPLAN, 2015, p. 9), distribuída num Centro Sub-Regional (Santo Ângelo), dois Centros de Zona (São Luiz Gonzaga e Cerro Largo) e nos demais municípios, considerados centros locais. Enquanto o Rio Grande do Sul, no período 2000-2010, registrou uma taxa de crescimento populacional de $0,49 \%$ ao ano, o COREDE Missões teve perda populacional, com uma média de crescimento demográfico de - 0,57\% ao ano, no 
mesmo período, sendo que apenas quatro (Cerro Largo, São Pedro do Butiá, Salvados das Missões e São Miguel das Missões) dos 25 municípios apresentaram taxas positivas de crescimento.

A saúde e a geração e apropriação de renda são outros pontos sensíveis, pois apresentam indicadores sociais com desempenhos preocupantes. Analisando-se os blocos do Índice de Desenvolvimento Socioeconômico (IDESE) da região, percebe-se que a Educação $(0,729)$ tem o melhor desempenho, superior inclusive à média estadual, ficando com a $7^{\mathrm{a}}$ posição no ranking dos 28 COREDEs gaúchos. Por outro lado, os Blocos Renda e Saúde "possuíam valores menores que a média do Estado com, respectivamente, 0,637 e 0,796” (SEPLAN, 2015, p. 14).

Em relação ao Produto Interno Bruto (PIB), a região das Missões apresentou, em 2012, um PIB de R \$ 4,6 bilhões, ou 1,6\% do total do Estado. O PIB per capita era, no mesmo ano, de R\$18.581,00 abaixo da média estadual (R\$ $25.779,00)$. Voltada mais ao setor primário, a região tem pouca participação na indústria, em relação à média estadual. No Valor Adicionado Bruto (VAB), "a Agropecuária detém 17,8\%, a Indústria possui apenas 16,6\%, e os Serviços, 65,6\%. Em relação à média do Estado, o COREDE possui maior participação da Agropecuária e menor da Indústria e dos Serviços" (SEPLAN, 2015, p. 16). O VAB do Rio Grande do Sul se divide em 66,3\% nos Serviços, $25,2 \%$ na Indústria e $8,4 \%$ na Agropecuária.

$\mathrm{Na}$ questão referente à logística, há deficiências na malha rodoviária, com cinco municípios ainda sem ligação asfáltica (Ubiretama, Eugênio de Castro, Garruchos, Pirapó e Rolador). O modal hidroviário é subaproveitado, e a malha ferroviária poderia ser explorada de maneira mais eficiente, contínua e racional. A região possui um "aeroporto regional” em Santo Ângelo, o qual, após longo processo de reformas e readequações, deve retomar a rotina de voos regulares entre Porto Alegre e Santo Ângelo, a partir de julho de 2017.

Quanto à infraestrutura de energia e comunicações, o estudo "Rumos 2015", elaborado pela SEPLAN, apontava que a região

apresentava várias linhas de transmissão de energia de alta e média capacidade, além de previsão de pequenas centrais hidrelétricas e parque eólico, não parecendo haver problemas de suprimento bruto, mesmo porque o consumo era muito baixo em quase todos os municípios (até $25 \mathrm{kWh}$ ), com exceção dos dois polos de Santo Ângelo e São Luiz Gonzaga (250 kWh). No entanto, ocorrem 
falhas de suprimento acima dos padrões aceitáveis, e o maior problema ocorre com a distribuição rural, em que a maior parte da Região tem atendimento de apenas até $75 \%$ dos domicílios. Considerando a forte base agropecuária da Região e o tipo de culturas, esse déficit contribui para diminuir a eficiência e potenciais modernizações nesse setor. (SEPLAN, 2015, p. 22).

Os dados do Censo 2010 referentes ao setor das comunicações, no âmbito do COREDE Missões, apontam "23,1\% dos domicílios com acesso à internet, $88,9 \%$ com celulares e $23,3 \%$ com telefonia fixa, enquanto as médias estaduais são, respectivamente, 33,9\%, 90,7\% e 39,3\%" (SEPLAN, 2015, p. 22).

No COREDE Missões há boa disponibilidade de recursos hídricos, que são utilizados para a produção de energia e para irrigação. "O rio Ijuí conta com a barragem Passo São João (77 MW) e a barragem Passo São José (51 MW). Há, na região, duas pequenas centrais hidrelétricas (PCHs): $\mathrm{PCH}$ Ijuizinho (1 MW), em Eugênio de Castro, e PCH Ijuizinho II (3,6 MW), em Entre-Ijuís, ambas instaladas no rio Ijuizinho" (SEPLAN, 2015, p. 22). Mesmo assim, a escassez hídrica é uma realidade não apenas no Estado, mas nessa região também, pois entre 1991 e 2010, de acordo com os registros de desastres naturais, ocorreram estiagem e seca em todos os municípios do COREDE, além da ocorrência de vendavais, ciclones, granizo e inundações bruscas. "As estiagens periódicas em épocas de grande demanda por recursos hídricos fazem a oferta de água diminuir drasticamente, levando ao estabelecimento de conflitos crescentes pelo uso do recurso" (SEPLAN, 2015, p. 24). Como é uma tendência, a escassez de água pode inviabilizar atividades econômicas e sociais, prejudicando o desenvolvimento, sendo fundamental que ações de gestão sejam cada vez mais estimuladas para o uso racional desse recurso, até mesmo em função da base da economia regional estar ligada à produção primária.

Em relação às condições ambientais e de saneamento, a região apresenta muitas deficiências, "principalmente no número de banheiros ou sanitários ligados à rede geral ou fossa séptica" (SEPLAN, 2015, p. 8), ao tratamento de efluentes urbanos e ao recolhimento e tratamento de resíduos sólidos.

\section{Desafios no saneamento básico e na coleta de resíduos sólidos}

Um dos entraves ao desenvolvimento na região das Missões é, sem dúvida, os problemas que envolvem o saneamento básico e a coleta de resíduos 
sólidos urbanos que, por ser tema principal deste estudo, serão analisados com mais profundidade.

O abastecimento urbano de água, conforme dados de 2010 da Agência Nacional de Água (ANA), precisa ser ampliado em seis municípios (Roque Gonzales, Santo Antônio das Missões, São Nicolau, Sete de Setembro, Bossoroca e Guarani das Missões). Nos demais 19 municípios, o abastecimento é considerado satisfatório. Porém, esse satisfatório não indica níveis de excelência, que precisam ser buscados, especialmente em épocas de estiagem. A Companhia Riograndense de Saneamento (CORSAN) é responsável pelos serviços de água e esgoto em 13 municípios, enquanto nos outros 12 os serviços são responsabilidade de departamentos municipais. Com relação a tratamento de esgoto, apenas Santo Ângelo conta com esse serviço, porém atendendo não mais do que $20 \%$ das residências (ANA, 2010). O perfil socioeconômico traz dados que demonstram que a região das Missões apresenta, em média, 90,81\% dos domicílios ligados à rede geral de água. Cabe destacar que esse percentual é superior às médias do Estado (85,33\%) e do Brasil (82,85\%). E as taxas variam de 65,36\% (São Miguel das Missões) a 97,98\% (Salvador das Missões).

Mesmo com uma ótima média em relação a "domicílios ligados à rede geral de água", superior às médias estadual e nacional, os dados demonstram que existe uma oscilação bastante considerável na prestação desse serviço essencial. Se 18 municípios têm índice superior a 90\%, destacando-se Salvador das Missões (97,98\%), Guarani das Missões (97,52\%), Caibaté (97,27\%), Dezesseis de Novembro (97,08\%) e Cerro Largo (97\%), quatro municípios aparecem com índices inferiores a 80\%: São Miguel das Missões (65,36\%), Bossoroca (76,66\%), Santo Antônio das Missões (77,04\%) e Entre-Ijuís (77,56\%). Há, portanto, a necessidade de empreender esforços para a universalização desse serviço. Os dados disponibilizados pelo perfil socioeconômico mostram, ainda, que "persistem outras formas de abastecimento nos domicílios do COREDE, como a utilização de poço ou nascente na propriedade ou fora dela, rio, açude e lago" (SEPLAN, 2015, p. 28).

No item relativo a "domicílios com banheiro ou sanitário ligado à rede geral ou fossa séptica”, os dados do Censo Demográfico de 2010 apresentam uma situação preocupante, pois a média de $26,41 \%$ é muito inferior às médias estadual $(74,57 \%)$ e nacional $(67,06 \%)$. Aliás, o município que chegou mais perto 
da média nacional foi Rolador (59,82\%), enquanto Guarani das Missões e Garruchos apresentaram médias insignificantes, respectivamente de $4 \%$ e $5,41 \%$. Dos 25 municípios, 16 ficaram abaixo de 30\%, enquanto apenas dois superaram a média de 50\% (Rolador, com 59,82\% e São Luiz Gonzaga, com 58,65\%).

E no item "domicílios com coleta de lixo por serviços de limpeza ou caçamba", igualmente com dados do Censo Demográfico 2010, mais uma vez os números do COREDE Missões são insatisfatórios. A média regional de 62,05\% é inferior às médias estadual (92,08\%) e nacional (87,41\%), apresentando valores entre $22,31 \%$ (Ubiretama) e 95,08\% (Cerro Largo), evidenciando-se a necessidade de esforços para a universalização desse serviço. Enquanto apenas três municípios ficaram com média superior a 90\% (Cerro Largo, com 95,08\%, Santo Ângelo, com 94,94\% e São Luiz Gonzaga, com 90,74\%), um total de 13 municípios ficaram com médias abaixo de $60 \%$, com destaque negativo para Ubiretama (22,31\%), Vitória das Missões (22,37\%) e Rolador (28,36\%). O problema agrava-se ainda mais se considerarmos que se trata apenas de coleta urbana, $\mathrm{e}$ os municípios da região, em sua maioria, apresentam índices de mais de $40 \%$ de sua população residindo no meio rural.

O Ministério das Cidades informa "que apenas 31\% dos municípios brasileiros têm o Plano Municipal de Saneamento Básico (PMSB) - que estabelece diretrizes para que o país alcance a universalização dos serviços no setor, segundo a Lei n ${ }^{\circ} 11.445$ " (TRATA BRASIL, 2015). Inicialmente, os municípios tinham até dezembro de 2015 para elaborarem seus PMSB, mas por meio do Decreto ${ }^{\circ}$ 8.629/2015 esse prazo foi dilatado até dezembro de 2017. No Rio Grande do Sul, conforme a Pesquisa PMSB no Rio Grande do Sul, elaborada pelo Departamento de Saneamento da Secretaria de Habitação e Saneamento do RS (DESAN), 103 municípios gaúchos declararam possuir o plano de saneamento concluído, enquanto 72 declararam estar em fase de elaboração. E, analisando o Anexo IX do referido estudo, verifica-se que na região do COREDE Missões, apenas Bossoroca está com seu PMSB completo (DESAN, 2014, p. 70), o que não deixa de ser uma informação preocupante.

Em pelo menos oito dos 25 municípios está implantada a coleta seletiva de resíduos sólidos urbanos. "Segundo a Política Nacional de Saneamento Básico (PNSB), em 2008, os municípios de Entre-Ijuís, Giruá, Guarani das Missões, Roque Gonzales, Santo Ângelo, São Luiz Gonzaga, São Miguel das Missões e 
Sete de Setembro já realizavam coleta seletiva" (SEPLAN, 2015, p. 29), ação que, somada a alternativas de aproveitamento e reciclagem, colabora para a redução dos volumes de resíduos sólidos e rejeitos encaminhados para aterros sanitários e aterros controlados. $\mathrm{O}$ documento ressalta, porém, que persistem em quase todos os municípios práticas inadequadas de deposição de resíduos.

\section{CONSTRUINDO ALTERNATIVAS NA COLETA E DESTINAÇÃO DOS RSU}

Os indicadores apresentados pelos municípios do COREDE Missões no perfil socioeconômico demonstram que a média regional de domicílios com coleta de resíduos sólidos urbanos $(62,05 \%)$ é bem inferior às médias estadual $(92,08 \%)$ e nacional $(87,41 \%)$. Mesmo Cerro Largo, que aparece com o excelente índice de 95,08\%, não deixa de apresentar sérios problemas nesse setor. Com o "lixão municipal" interditado pela Fundação Estadual de Proteção Ambiental Henrique Luiz Roessler (FEPAM) e com entraves técnicos e burocráticos para habilitar uma área recentemente adquirida, para fazer a separação dos resíduos e o transbordo, o município é mais um que envia os resíduos sólidos recolhidos na cidade e no interior para aterro sanitário privado, da Companhia Riograndense de Valorização de Resíduos, localizado na rodovia VRS-867, km 2, em Giruá, a um custo mensal de aproximadamente R $\$ 52$ mil, de acordo com dados oficiais da Secretaria de Administração.

A coleta seletiva, que poderia reduzir o volume de resíduos enviados a Giruá (com redução nas despesas mensais) e aumentar o volume de resíduos recicláveis, com incremento no faturamento dos catadores, é uma questão que vem sendo tentada há bastante tempo em Cerro Largo. O jornal Folha da Produção, em sua edição no 1.099, de 28 de outubro de 1993, noticiou que:

Alunos do $2^{\circ}$ ano do segundo grau do Colégio Medianeira de nossa cidade, acompanhados pela professora Simoni Priesnitz, foram recebidos na manhã da última sexta-feira pelo prefeito Adair Trott, ao qual foram apresentar um projeto de coleta seletiva de lixo, propondo assim uma maneira de aproveitar melhor a usina de reciclagem já existente no município, e facilitando o trabalho dos próprios funcionários. Ainda neste mês, os alunos pretendem fazer uma consulta junto à população para conhecer a opinião de cada um, no sentido de 
separar o lixo orgânico e inorgânico. Tal projeto deverá ser colocado em prática imediatamente, tão logo esteja terminada a consulta popular (1993, p. 1).

Depois, na gestão 2009/2012, a Prefeitura de Cerro Largo lançou nova campanha para a coleta seletiva, com distribuição de farto material gráfico e inserção de publicidade em diversos tipos de mídia. A Folha da Produção, em sua edição $\mathrm{n}^{\circ}$ 2.014, de 5 de maio de 2011, trouxe a informação do lançamento de um projeto de coleta e reciclagem de gordura saturada. No texto, o então prefeito Adair José Trott lembrou outro problema ligado ao meio ambiente, que é a coleta de lixo, e adiantou "que possivelmente até o final do ano, dependendo da liberação de recursos federais, poderá estar implantada a nova unidade para a coleta e separação do lixo em nossa cidade" (2011, p. 5).

Como se viu, nas últimas décadas foram feitas várias tentativas de implantar a coleta seletiva em Cerro Largo, ora por iniciativa de escolas ou entidades locais, ora por iniciativa do município. Mais de um projeto foi implantado, mas eles não tiveram continuidade. Uma usina de reciclagem adquirida pela municipalidade acabou tornando-se obsoleta e desativada, tendo operado em curtos períodos de tempo. E a nova unidade para coleta e separação do lixo, a ser instalada em área adquirida junto à localidade denominada Linha Primeira, no interior do município, nunca chegou a operar por falta de licenciamento ambiental.

Verifica-se ainda que a simples implantação da coleta seletiva não é suficiente, se não estiver acompanhada de outras medidas, como a sensibilização da comunidade para adesão à iniciativa, e a possibilidade, por intermédio de ações diretas e indiretas, dos catadores terem um melhor aproveitamento dos resíduos sólidos urbanos recicláveis, a fim de gerar um duplo benefício: maior volume comercializável (com mais renda para os catadores) e menor volume para a destinação final (com menos despesa para o Município).

Recentemente foi criada a Incubadora Tecnossocial de Cooperativas e Empreendimentos Econômicos Solidários (ITCEES), que é um laboratório da Universidade Federal da Fronteira Sul (UFFS) - Campus Cerro Largo e desenvolve vários projetos e atividades, sendo um braço de atuação da universidade. Dentro da Incubadora há o Fórum de Gestão Social, com foco em questões sociais e ambientais, que desenvolve o programa de extensão "Educação ambiental nas escolas e na comunidade de Cerro Largo visando um meio ambiente 
ecologicamente equilibrado - Pensar o Amanhã”, que, por sua vez, é composto por três comitês temáticos. Um comitê técnico está trabalhando em soluções e alternativas para o problema da destinação final dos RSU em Cerro Largo. Outro comitê atua para formação de uma cooperativa de catadores, que já está formada - a Cooperativa dos Catadores Unidos Pela Natureza (COOPERCAUN) - e encontra-se em fase de implantação. E há ainda o comitê de educação ambiental, que faz atividades educativas nas escolas, capacitação para os catadores e a sensibilização da comunidade para a questão da coleta seletiva.

Um dos resultados práticos do programa "Pensar o Amanhã", que deve ser desenvolvido num período inicial de quatro anos, é que após tratativas com o município será retomada a coleta seletiva em Cerro Largo, com participação direta da cooperativa dos catadores recentemente formada, e uma ampla campanha comunitária para sensibilização da comunidade, com o envolvimento de diversas entidades e instituições parceiras. Espera-se que, dessa vez, a coleta seletiva tenha atuação perene e vida longa em Cerro Largo.

\section{Consórcios públicos e a PNRS}

O perfil socioeconômico do COREDE Missões destaca que "a gestão dos resíduos sólidos costuma ser um problema para os pequenos municípios, principalmente no que tange ao manejo e à disposição final” (SEPLAN, 2015, p. 29). Essa dificuldade leva "o poder público a soluções dispendiosas, como enviar o lixo produzido para empresas privadas que gerenciam aterros sanitários" (FRANQUI, 2016, p. 2).

A partir da Constituição Cidadã de 1988, ao reconhecer o município como ente federado, foi traçada uma maior complexidade ao modelo federativo do país, seguindo-se intensa descentralização de políticas públicas. Desde então, diversas formas de consorciamento foram implantadas no país, mas apenas em 2003 o governo federal começou a debater mais efetivamente a legislação dos consórcios, que resultou na Lei 11.107, de 2005.

Os consórcios contam com amparo constitucional, previstos no artigo 241 da Carta Magna, em cujos termos “a União, os Estados, o Distrito Federal e os Municípios disciplinarão por meio de lei os consórcios públicos e os convênios de cooperação entre os entes federados, autorizando a gestão associada de serviços 
públicos, bem como a transferência total ou parcial de encargos, serviços, pessoal e bens essenciais à continuidade dos serviços transferidos" (BRASIL, 2016, p.78).

Como salienta Franqui (2016, p. 3), basicamente os consórcios públicos atendem a dois objetivos: "viabilizar a gestão pública nas regiões metropolitanas, onde a solução de problemas equivalentes é mais viável através de ações políticas coletivas, e permitir que pequenos municípios formem parcerias para, com o ganho em escala, ter redução de custos e melhor capacidade gerencial sobre questões em comum”. Por sua vez, Barros (1995, p. 53) enfatiza que os consórcios intermunicipais podem ser "instrumentos eficazes de desenvolvimento regional em qualquer dos quadrantes econômicos do estado, sob a condição de que sejam concebidos, estruturados e conduzidos em consonância com as peculiaridades de cada realidade territorial distinta".

Fazendo uma análise sobre os resultados que podem ser alcançados com a criação de consórcios, destaca-se: o aumento da capacidade de realização, ampliando o atendimento ao cidadão; maior eficiência do uso dos recursos públicos, no caso em que a função central é compartilhar máquinas, unidades de saúde ou unidades para a disposição final de resíduos sólidos; realização de ações inacessíveis a um único município, como a aquisição de equipamentos de alto custo; aumento do poder de diálogo, pressão e negociação dos municípios, com melhores condições de negociação junto aos governos estadual e federal ou mesmo as entidades da sociedade civil, empresas ou agências estatais; e aumento da transparência das decisões públicas, pois exigem um processo de discussão mais aprofundado e possibilitam uma maior fiscalização, em todos os municípios envolvidos (AMORIM, 2008).

A experiência com a implantação de consórcios públicos pelo país, nas mais diversas áreas, tem se mostrado eficiente, no sentido de minimizar custos e maximizar resultados. Para Amorim (2008), o consórcio público é um mecanismo que "oferece de resolução de problemas e de implementação de ações de interesse comum, garantindo respostas eficientes a problemas comuns".

O artigo 54 da PNRS foi claro ao determinar que "a disposição final ambientalmente adequada dos rejeitos, observado o disposto no $\$ 1^{\circ}$ do art. $9^{\circ}$, deverá ser implantada em até 4 (quatro) anos após a data de publicação desta Lei" (2 de agosto de 2010). Esse objetivo não foi atendido em sua totalidade e, no momento, os debates no campo político e na sociedade civil organizada ocorrem 
em duas principais frentes: viabilizar o cumprimento imediato do estabelecido ou dilatar os prazos, por meio de projeto de lei, dando mais tempo para que Estados e Municípios possam se adequar às disposições legais.

Na região Celeiro do Rio Grande do Sul, há o Consórcio Intermunicipal de Tratamento de Resíduos Sólidos Urbanos (CITRESU), que abrange 11 municípios $^{7}$. O consórcio iniciou suas atividades em abril de 2000 e, após a realização de estudos técnicos ambientais, de localização e de custo de transporte, foi definido o melhor local para instalação da central de triagem e do aterro, localizado no município de Bom Progresso. Esses 11 municípios representam aproximadamente $40 \%$ da área da região Celeiro e possuem em torno de $53 \%$ da população regional. A atuação do CITRESU está articulada em três eixos principais: separação doméstica dos resíduos sólidos, incentivada por meio de campanhas de sensibilização em cada município; coleta seletiva orientada pelas prefeituras, não cabendo ao consórcio definir a forma de realização da coleta (pode ser por empresa privada ou pela própria municipalidade); e o tratamento e destino dos resíduos sólidos, eixo este gerenciado pelo consórcio, responsável pela triagem, seleção e destinação final. Weber (2009, p. 72) destaca que "para os Municípios partícipes do CITRESU, o consórcio resultou no fim dos 'lixões', promovendo adequação à legislação ambiental, diminuição de custos para o tratamento do lixo, beneficiando toda a população".

É fato que poucos municípios integrantes do COREDE Missões vislumbraram o consórcio público intermunicipal como uma alternativa efetiva para a gestão dos RSU. O perfil socioeconômico registra duas iniciativas animadoras na região, com seis dos 25 municípios apostando nesse tipo de política pública para o gerenciamento dos resíduos sólidos. Guarani das Missões e Sete de Setembro "formam o Consórcio Intermunicipal de Resíduos Sólidos Urbanos (Comandaí), que atende, considerando a população dos dois municípios, aproximadamente 10.239 pessoas" (SEPLAN, 2015, p. 29), enquanto São Nicolau, Dezesseis de Novembro, Pirapó e Porto Xavier, com uma população total de 21.908 habitantes, constituíram o Consórcio Intermunicipal de Resíduos Sólidos (CRESU), com sede em São Nicolau, que mantém um aterro sanitário devidamente licenciado

7 Bom Progresso, Braga, Campo Novo, Crissiumal, Esperança do Sul, Humaitá, São Martinho, Sede Nova, Tiradentes do Sul, Três Passos e São Valério do Sul. 
pela FEPAM, localizado no Rincão dos Maciel, uma localidade interiorana entre São Nicolau e Pirapó.

O perfil socioeconômico do COREDE Missões deixa evidente que os municípios missioneiros ainda estão longe de atender às determinações da PNRS. Diante desse desafio, uma das soluções possíveis, no que tange ao gerenciamento e à destinação final dos RSUs pode ser atuar de maneira associativa, por meio de consórcios públicos intermunicipais, que já contam com duas iniciativas embrionárias nesta região e que podem ser estendidas, inclusive, fundadas nas experiências de regiões próximas, como a Celeiro.

\section{CONSIDERAÇÕES FINAIS}

Entre tantas conceituações existentes sobre política pública, não sendo nenhuma melhor ou mais completa, Souza $(2003$, p.13) entende que política pública é o "campo do conhecimento que busca, ao mesmo tempo, colocar o governo em ação e/ou analisar essa ação". Para a autora (2003, p. 13), "o processo de formulação de política pública é aquele através do qual os governos traduzem seus propósitos em programas e ações, que produzirão resultados ou as mudanças desejadas no mundo real". Mas Secchi $(2016$, p. 5) lembra que "dois conceitos são fundamentais para entender o campo da política pública: o problema público e a política pública. O primeiro trata do fim ou da intenção de resolução. O segundo trata do meio ou mecanismo para levar a cabo tal intenção". Metaforicamente, o problema público seria a "doença" e, portanto, necessita de um diagnóstico preciso para ser corretamente medicada pelo "remédio", no caso a política pública.

Neste capítulo foram analisados dois problemas públicos no âmbito do COREDE Missões - o saneamento básico e, mais especificamente, a coleta de resíduos sólidos urbanos, bem como sua destinação final. E procurou-se apontar políticas públicas adequadas para superar esses entraves - verdadeiros gargalos - para o desenvolvimento regional.

Mesmo que a maioria dos municípios que integram a área de abrangência do COREDE Missões seja formada por núcleos urbanos com menos de 10.000 habitantes, os dados analisados apontam para a "ausência de infraestrutura de esgotos e os baixos índices dos municípios de domicílios com banheiro ou 
sanitário ligado à rede geral ou fossa séptica até 2010" (SEPLAN, 2015, p. 33). Também foi constatado que apenas um município da região, Bossoroca, declarou estar com seu Plano Municipal de Saneamento Básico concluído, cujo prazo para elaboração a todos os municípios do país se esgota em dezembro de 2017.

Também ficou evidenciado que a coleta de resíduos sólidos urbanos por serviço de limpeza ou caçamba é bastante inferior às médias estadual e nacional, sendo que em apenas oito dos 25 municípios da região analisada foi implantada a coleta seletiva. Assim como as dificuldades que os municípios têm na disposição final dos resíduos sólidos urbanos, fazendo a destinação para aterros privados, e o embaraço em adequar-se à legislação vigente, notadamente à Política Nacional de Resíduos Sólidos, reeditando uma realidade que infelizmente faz parte de enorme contingente de cidades brasileiras.

Diante das dificuldades verificadas no gerenciamento dos RSU, a implantação de sistemas de coleta seletiva, a formação de cooperativas de catadores e o consorciamento são boas alternativas para os municípios cumprirem essa imposição, com vistas a reduzir custos e maximizar resultados e, dessa forma, atender às exigências de eficiência do poder público, tão reclamada pela sociedade, e ainda colaborar com um meio ambiente equilibrado e sustentável.

Para que esses objetivos sejam alcançados é necessária uma articulação entre conscientização dos moradores, atuação dos catadores, do poder público e das organizações da sociedade civil. Sem isso não haverá solução efetiva e de longo prazo.

\section{REFERÊNCIAS}

ABRAMOVAY, Ricardo; SPERANZA, Juliana Simões; PETITGAND, Cécile. Lixo Zero, Gestão de resíduos sólidos para uma sociedade mais próspera. São Paulo: Planeta Sustentável, Instituto Ethos, 2013.

ABRELPE. Panorama dos Resíduos Sólidos no Brasil 2014. Disponível em: http://www.abrelpe.org.br/Panorama/panorama2014.pdf. Acesso em: 10 mar. 2017.

AGÊNCIA NACIONAL DE ÁGUAS (ANA). Atlas Brasil: Abastecimento Urbano de Água. 2010. Disponível em: http://atlas.ana.gov.br/Atlas/forms/ Home.aspx. Acesso em: 19 nov. 2016. 
AMORIM, Maria Raquel Machado de Aguiar Jardim de. Consórcios Públicos: O Poder de diálogo das prefeituras junto aos governos estadual e federal. Disponível em: http://www.imb.go.gov.br/pub/conj/conj8/10.htm. Acesso em: 15 nov. 2016.

BARROS, Pedro Motta de. Consórcio intermunicipal: ferramenta para o desenvolvimento regional. São Paulo: Alfa Ômega, 1995.

BAUMAN, Zygmunt. Trabajo, consumismo y nuevos pobres. Barcelona: Gedisa, 2000.

BRASIL. Constituição Federal de 1988. Porto Alegre: CORAG, 2016. . Lei $\mathrm{n}^{\circ} 11.445$, de 5 de janeiro de 2007. Estabelece diretrizes nacionais para o saneamento básico. Disponível em: http://www.planalto.gov. br/ccivil_03/_ato2007-2010/2007/lei/11 1445.htm. Acesso em: 15 nov. 2016. . Lei $\mathrm{n}^{\circ} 12.305$, de 2 de agosto de 2010. Institui a Política Nacional de Resíduos Sólidos; altera a Lei no 9.605, de 12 de fevereiro de 1998; e dá outras providências. Disponível em: http://www.planalto.gov.br/ccivil_03/_ ato2007-2010/2010/lei/112305.htm. Acesso em: 15 nov. 2016.

FRANQUI, Luís Henrique Teixeira. Projeto de coleta e reciclagem de gordura saturada lançado oficialmente terça-feira. Folha da Produção, Cerro Largo, 5 maio 2011, p. 5.

Consórcio Intermunicipal de Resíduos Sólidos: estudo de caso em São Nicolau. In: SEMINÁRIO DE PESQUISA, EXTENSÃO E INICIAÇÃO CIENTÍFICA DO IESA/CNEC, II, 2016. Anais. Santo Ângelo: EDIESA.

INCUBADORA TECNOSSOCIAL DE COOPERATIVAS E EMPREENDIMENTOS ECONÔMICOS SOLIDÁRIOS. Resolução 01/2015 do Conselho do Campus. Regimento Interno. Cerro Largo: UFFS, 2015.

ONU. Declaração de Estocolmo sobre o ambiente humano (1972).

Disponível em: http://www.direitoshumanos.usp.br/index.php/MeioAmbiente/declaracao-de-estocolmo-sobre-o-ambiente-humano.html. Acesso em: 19 nov. 2016.

RAMOS, Antônio Dari. A formação histórica dos municípios da região das Missões do Brasil. Santo Ângelo, 2006. Disponível em: http://www.urisan. tche.br/ iphan/upload/downloads/file1.pdf. Acesso em: 10 mar. 2017.

ROTTA, Edemar et al. Desenvolvimento e Ambiente em Planejamentos Municipais: Missões e Fronteira Noroeste do Rio Grande do Sul. In: SEMINÁRIO INTERNACIONAL SOBRE DESENVOLVIMENTO REGIONAL, VII Anais. Santa Cruz do Sul, 2015. 
SANTOS, Edson. Alunos ajudam a reciclar o lixo. Folha da Produção, Cerro Largo, 28 out. 1993, p. 1.

SECCHI, Leonardo. Análise de Políticas Públicas: diagnóstico de problemas, recomendação de soluções. São Paulo: Cengage Learning, 2016.

SECRETARIA DO PLANEJAMENTO, MOBILIDADE E DESENVOLVIMENTO REGIONAL DO RS. Perfil socioeconômico COREDE Missões. Disponível em: http://planejamento.rs.gov.br/upload/ arquivos/201603/28140705-perfis-regionais-2015-missoes.pdf. Acesso em: 19 nov. 2016.

SECRETARIA DE HABITAÇÃO E SANEAMENTO DO RS. Resultados Pesquisa Planos Municipais de Saneamento no Rio Grande do Sul. Disponível em: http://www.mprs.mp.br/areas/ressanear/arquivos/ materialtecrs/estudo_planos_saneam_sehabs_caourb.pdf. Acesso em 10 mar. 2017.

SOUZA, Celina. Políticas Públicas: questões temáticas e de pesquisa. Caderno CRH, Salvador, n. 39, p. 11-24, jul./dez. 2003.

TRATA BRASIL. Só 31\% dos municípios brasileiros têm Plano Municipal de Saneamento Básico. Disponível em: http://tratabrasil.org.br/so-31dos-municipios-brasileiros-tem-plano-municipal-de-saneamento-basicosegundo-ministerio-das-cidades. Acesso em: 10 mar. 2017.

WEBER, Daniel. Consórcio Intermunicipal de Tratamento de Resíduos Sólidos da Região Celeiro do Estado do Rio Grande do Sul: uma nova institucionalidade para as políticas de desenvolvimento regional. Dissertação (Mestrado em Desenvolvimento Regional), Universidade Regional de Blumenau (FURB), Blumenau, 2009.

WORLD BANK. What a Waste: A Global Review of Solid Waste Management. Disponível em: https://openknowledge.worldbank.org/ handle/10986/17388. Acesso em: 10 mar. 2017. 


\section{COMITÊ CIENTÍFICO INTERNACIONAL RED CIDIR}

Dra. Antonia Godoy (UNaM - Argentina)

Dra. Liliana Dieckow (UGD - Argentina)

Dra. Márcia A. Dias Kraemer (FEMA - Brasil)

Dr. Alberto Riella (UdelaR - Uruguai)

Dr. Alfredo Dachary (UdG - México)

Dr. Ariosto Sparemberger (UNIJUÍ- Brasil)

Dr. Carlos Jardón (UVigo - Espanha)

Dr. Edemar Rotta (UFFS - Brasil)

Dr. Herton Castiglioni Lopes (UFFS - Brasil)

Ma. Cátia Guadagnin Rossa (FEMA - Brasil)

Esp. Gerson Miguel Lauermann (FEMA - Brasil)

Ma. Andréa Maria Cacenote (FEMA - Brasil)

Dra. Bianca Tams Diehl (FEMA - Brasil)

Ma. Claudia Martínez (UGD - Argentina)

Dra. Daniele Regina Terribile (FEMA - Brasil)

Dra. Louise de Lima R. Botelho (UFFS - Brasil)

Ma. Marina Laveran (UNaM - Argentina)

Ma. Rosa Encina Fretes (UCI - Paraguai)

Dra. Sinara Camera (FEMA - Brasil)

Me. Aldo Montini (UNaM - Argentina)

Me. Antonio R. Lausmann Ternes (FEMA - Brasil)

Dr. Carlos Eduardo Ruschel Anes (UFFS - Brasil)

Me. Jorge Ferrari (UGD - Argentina)

Me. Leandro Steiger (FEMA - Brasil)

Me. Luciano Zamberlan (UNIJUI - Brasil)

Me. Marcos Rogério Rodrigues (FEMA - Brasil)

Me. Marcos Volnei dos Santos (FEMA - Brasil)

Me. Miguel Angel Servin (UCI - Paraguai)

Me. Nedisson Luis Gessi (FEMA - Brasil)

Dr. Pedro Luís Büttenbender (UNIJUI - Brasil)

Me. Rodrigo Prante Dill (UFFS - Brasil)

PhD. Carlos E. Schvezov (UGD - Argentina) 


\section{Reitor Marcelo Recktenvald \\ Vice-Reitor Gismael Francisco Perin \\ Chefe do Gabinete do Reitor Suianny Francini Luiz Michelon}

Pró-Reitor de Administração e Infraestrutura Rafael Santin Scheffer

Pró-Reitor de Assuntos Estudantis Rubens Fey

Pró-Reitor de Gestão de Pessoas Claunir Pavan

Pró-Reitora de Extensão e Cultura Patricia Romagnolli

Pró-Reitor de Graduação Jeferson Saccol Ferreira

Pró-Reitora de Pesquisa e Pós-Graduação Clarissa Dalla Rosa

Pró-Reitor de Planejamento Everton Miguel da Silva Loreto

Secretária Especial de Laboratórios Cladis Juliana Lutinski

Secretário Especial de Obras Fábio Correa Gasparetto

Secretário Especial de Tecnologia e Informação Ronaldo Antonio Breda

Procurador-Chefe Rosano Augusto Kammers

Diretor do Campus Cerro Largo Bruno Munchen Wenzel

Diretor do Campus Chapecó Roberto Mauro Dall'Agnol

Diretor do Campus Erechim Luís Fernando Santos Corrêa da Silva

Diretor do Campus Laranjeiras do Sul Martinho Machado Júnior

Diretor do Campus Passo Fundo Julio César Stobbe

Diretor do Campus Realeza Marcos Antônio Beal 


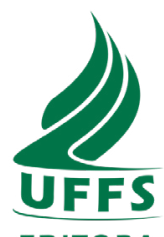

EDITORA

Diretor da Editora UFFS

Felipe Stanque Machado Junior

Chefe do Serviço de Publicações Editoriais

Fabiane Pedroso da Silva Sulsbach

Revisora de texto

Marlei Maria Diedrich

\section{Conselho Editorial}

Adelita Maria Linzmeier

Ademir Roberto Freddo

Andréia Machado Cardoso

Cláudio Claudino da Silva Filho

Crhis Netto de Brum

Demétrio Alvez Paz (Presidente)

Edemar Rotta

Eduardo Pithan

Izabel Gioveli

Jane Kelly Oliveira Friestino

Janete Stoffel

Jeane Barros de Souza

Leandro Henrique Manfredi

Liziara da Costa Cabrera

Marlon Brandt (Vice-presidente)

Roque Ismael da Costa Güllich

Rosangela Inês Matos Uhmann

Samira Peruchi Moretto

Siomara Aparecida Marques

Tiago Vecchi Ricci

Vanderléia Laodete Pulga

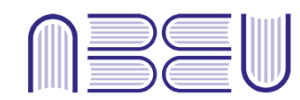

Associação Brasileira das Editoras Universitárias 


\author{
REVISÃO DOS TEXTOS Autores \\ PREPARAÇÃO E REVISÃO FINAL Marlei Maria Diedrich \\ PROJETO GRÁFICO E Mariah Carraro Smaniotto \\ DIAGRAMAÇÃO \\ CAPA Mariah Carraro Smaniotto (imagem Designed by \\ starline / Freepik)
}

DIVULGAÇÃO Diretoria de Comunicação

FORMATOS e-PUB, MOBI e PDF

C749 Conhecimento em rede: desenvolvimento, cooperação e integração regional em território de fronteira - Rede CIDIR : 10 anos / Organizadores Edemar Rotta ... [et al.]. - Chapecó, SC : Ed. UFFS, 2019. - 580 p. : il.

ISBN: 978-65-5019-012-5 (impresso)

978-65-5019-011-8 (e-book)

1. Redes de Universidades - América Latina - Brasil. 2. Ensino Superior - Brasil.

3. Rede de cooperação - Universidades. 4. Universidade - Desenvolvimento social. 5. Universidade - Desenvolvimento econômico. 6. Universidade Desenvolvimento sustentável. 7. Universidade - Interação regional. I. Rede Interuniversitária de Internacionalização do Conhecimento. II. Red CIDIR. III. Rotta, Edmar (Org.). IV. UFFS. 